\title{
COMPORTAMENTO DA DIARRÉIA INFANTIL ANTES E APÓS CONSUMO DE ÁGUA PLUVIAL EM MUNICÍPIO DO SEMI-ÁRIDO BRASILEIRO
}

\author{
Emanuella Silva Joventino ${ }^{1}$, Sabrina Ferreira da Silva², Raul Feitoza Rogerio ${ }^{3}$, Giselle Lima de Freitas ${ }^{4}$, Lorena \\ Barbosa Ximenes ${ }^{5}$, Escolástica Rejane Ferreira Moura ${ }^{6}$
}

\footnotetext{
${ }^{1}$ Mestranda do Programa de Pós-Graduação em Enfermagem da Universidade Federal do Ceará (UFC). Bolsista do CNPq. Prestadora de serviços do Hospital Geral de Fortaleza. Ceará, Brasil. E-mail: manujoventino@yahoo.com.br

${ }^{2}$ Enfermeira. Bolsista da Escola de Saúde Pública do Ceará. Ceará, Brasil. E-mail: duquezadesabri@hotmail.com

${ }^{3}$ Enfermeiro. Prestador de serviços do Hospital Geral de Fortaleza. Ceará, Brasil. E-mail: raultito@gmail.com

${ }^{4}$ Mestre em Enfermagem. Email: gisellelf@yahoo.com.br

${ }^{5}$ Doutora em Enfermagem. Docente do Departamento de Enfermagem da UFC. Ceará, Brasil. Pesquisadora do CNPq. E-mail: lbximenes2005@uol.com.br

${ }^{6}$ Doutora em Enfermagem. Docente do Departamento de Enfermagem da UFC. Ceará, Brasil. Pesquisadora do CNPq. E-mail: escolpaz@yahoo.com.br
}

\begin{abstract}
RESUMO: Objetivou-se investigar a correlação entre consumo de água das cisternas e comportamento da diarréia infantil. Estudo quantitativo, transversal, realizado em Canindé-CE, com 56 famílias. As principais fontes de água utilizadas antes da construção das cisternas foram cacimbão (21-37,5\%) e açude (17-30,4\%). Verificou-se correlação linear, inversamente proporcional e estatisticamente significante, entre a taxa de diarréia infantil e o número de cisternas construídas por ano $(\mathrm{r}=-0,943 ; \mathrm{p}=0,001)$. A cloração foi o principal tipo de tratamento da água, antes (46-82,1\%) e depois (37-66\%) da aquisição das cisternas, porém com diluição incorreta (41-89,2\%). As cisternas de captação de água pluvial refletiram na melhoria da saúde infantil na região, contudo a população ainda necessita melhorar as medidas de tratamento da água consumida.
\end{abstract}

DESCRITORES: Diarréia infantil. Abastecimento rural de água. Tratamento da água. Água potável. Enfermagem.

\section{BEHAVIOR OF CHILDHOOD DIARRHEA BEFORE AND AFTER CONSUMPTION OF RAINWATER IN THE CITY OF SEMI-ARID OF BRAZIL}

\begin{abstract}
Aimed to investigate the correlation between water tanks and infant diarrhea. Quantitative and transversal study, held in Canindé-CE, Brazil, with 56 families. The main sources of water used before the construction of tanks were "cacimbão" (21-37.5\%) and dam (17-30.4\%). There was a linear inverse correlation and relation statistically significant between the rates of infant diarrhea and the number of tanks built $(\mathrm{r}=-0.943 ; \mathrm{p}=0.001)$. Chlorination was the main type of water treatment before $(46-82,1 \%)$ and after $(37-66 \%)$ of the acquisition of the tank, but with incorrect dilution $(41-89,2 \%)$. Tanks to capture rainwater reflected in an improvement of child health in the region, but people still need to improve the treatment steps of water to be consumed.
\end{abstract}

DESCRIPTORS: Diarrhea, infantile. Water supply, rural. Water treatment. Potable water. Nursing.

\section{COMPORTAMIENTO DE LA DIARREA INFANTIL ANTES Y DESPUÉS DEL CONSUMO DEL AGUA DE LA LLUVIA EN UNA CIUDAD BRASILEÑA DE REGIÓN SEMI-ÁRIDA}

\footnotetext{
RESUMEN: El estudio tuvo como objetivo investigar la correlación entre el consumo de agua de los tanques y el comportamiento de la diarrea infantil. Es un estudio cuantitativo, transversal, realizado en Canindé-CE, Brasil, con 56 familias. Las principales fuentes de agua utilizadas antes de la construcción de los tanques, fueron "cacimbão" (21-37,5\%) y presa (17-30,4\%). Se verificó una correlación linear inversa y estadísticamente significativa entre las tasas de diarrea infantil y el número de tanques construidos por año $(r=-0,943 ; \mathrm{p}=0,001)$ y estadísticamente significativa $(\mathrm{p}=0,001)$. La cloración fue el principal tratamiento del agua antes $(46-82,1 \%)$ y después $(37-66 \%)$ de la adquisición del tanque, pero con dilución incorrecta (41-89,2\%). El uso de las cisternas para captar el agua de la lluvia se refleja en la mejora de la salud infantil en la región, sin embargo, las personas todavía necesitan mejorar las medidas para el tratamiento del agua potable.

DESCRIPTORES: Diarrea infantil. Abastecimiento rural de agua. Tratamiento del agua. Agua potable. Enfermería.
} 


\section{INTRODUÇÃO}

Inúmeros problemas ambientais são marcados pela intervenção humana sobre a natureza, destruição de ambientes silvestres e níveis de poluição elevados, os quais influenciam na qualidade de vida da humanidade, pois a degradação ambiental constituise em uma ameaça aos sistemas de suporte a vida. Esses fatores podem repercutir, por exemplo, na irregularidade das chuvas, na baixa qualidade dos recursos hídricos disponíveis e, consequentemente, na escassez de bens naturais básicos como a carência de água adequada para o consumo humano. ${ }^{1}$

A água é o componente líquido essencial para a manutenção da vida. Cerca de $60 \%$ do corpo humano é constituído por este recurso natural. Assim, o indivíduo pode passar semanas sem ingerir comida, mas, semágua, em dois dias inicia-se o processo de falência múltipla dos órgãos, podendo levar uma criança a óbito em cinco dias e um adulto em dez dias. ${ }^{2}$

A água é distribuída de forma irregular no planeta, sendo a demanda igualmente heterogênea. Assim, as condições atuais de disponibilidade e consumo mostram que, na maior parcela do território brasileiro, não há insuficiência de recursos hídricos, apesar das condições críticas em períodos de estiagem em algumas regiões como é o caso do semi-árido brasileiro, sobretudo do Nordeste. Esta região possui condições hídricas desfavoráveis, como a baixa e irregular pluviosidade, evapotranspiração elevada durante todo o ano e subsolo cristalino que acumula, em geral, água salobra. Tais condições representam fatores limitantes para o desenvolvimento econômico e social da região, além de contribuírem para o aumento da freqüência de doenças de veiculação hídrica e deficiências nutricionais na população. ${ }^{3}$

A Organização Mundial de Saúde (OMS) e o Fundo das Nações Unidas para a Infância (UNICEF) corroboram ao afirmarem que 4.500 crianças com menos de cinco anos de idade morrem, diariamente, no mundo, devido à dificuldade de acesso à água potável e à ausência de saneamento básico. ${ }^{4}$

Considerando que as doenças diarréicas estão diretamente relacionadas, sobretudo, com as condições de abastecimento hídrico, saneamento básico e higiene, verificou-se que, em 2004, o Nordeste brasileiro foi responsável por $56 \%$ dos óbitos em menores de cinco anos ocorridos no país. ${ }^{5}$ Além disso, a diarréia infecciosa afeta de forma dramática a saúde das crianças, gerando sobrecarga considerável aos serviços hospitalares ${ }^{6}$, sendo considerado este fato como inaceitável por ser uma doença prevenível através da garantia de condições básicas de vida.
Sabe-se que relacionar saúde e ambiente no aspecto socioambiental implica na necessidade de se problematizar o sentido de ambiente em sua dimensão física e social, encarando-o como determinante/condicionante do processo saúde-doença da população. Para tanto, a própria comunidade e profissionais da saúde devem compreender as situações ambientais em que estão inseridos para que, assim, possam trabalhar mais efetivamente esta relação existente entre saúde e ambiente. ${ }^{7}$

Nesse contexto, vem sendo implantada no semi-árido brasileiro uma estratégia sustentável, que tem como foco melhorar o acesso de famílias à água potável, denominada "Programa de Formação e Mobilização Social para a Convivência com o Semi-Árido: Um Milhão de Cisternas Rurais (P1MC)". Este programa consiste na construção de cisternas de placas com capacidade para armazenar 16.000 litros de água de origem pluvial, volume suficiente para o consumo doméstico de uma família de cinco pessoas durante um ano. ${ }^{8}$

Entretanto, mesmo com a implantação do P1MC, não se tem a garantia de que as famílias beneficiadas estejam utilizando a água proveniente das cisternas de maneira adequada, fazendo-se imperativo o trabalho do profissional enfermeiro no que concerne à prevenção de doenças, sobretudo as de veiculação hídrica, bem como às estratégias de promoção da saúde que priorizem ações empoderadoras dessas famílias, de maneira que as mesmas tornemse co-participantes do seu processo de cuidado.

Assim, objetivou-se descrever as principais fontes de água utilizadas pelas famílias estudadas para o consumo humano, antes da construção das cisternas; investigar a correlação entre o consumo de água das cisternas e o comportamento das diarréias em crianças menores de cinco anos pertencentes às famílias beneficiadas pelo P1MC; além de verificar o tipo de tratamento dispensado à água consumida pelas famílias, antes e após a construção das cisternas.

\section{MATERIAIS E MÉTODOS}

Estudo quantitativo e transversal realizado em março de 2008, na cidade de Canindé, situada na região semi-árida do Sertão Central do Ceará. No município, estão instaladas 281 cisternas originadas do P1MC, correspondendo, pois, a 281 famílias beneficiadas pelo Programa.

Para que uma família receba a cisterna do P1MC, exige-se que um dos membros da mesma assista ao curso de Gestão de Recursos Hídricos 
(GRH) oferecido pelo Programa. Assim, os critérios de inclusão para o estudo foram: possuir cisterna do P1MC; o representante da família, participante do referido curso, encontrar-se no domicílio no momento da entrevista; além de aceitar participar da pesquisa.

Sendo assim, a amostra foi determinada com base na fórmula para o cálculo de populações finitas $(n=72)$. Todavia, encontraram-se alguns obstáculos para a realização do estudo, tais como: a dificuldade de acesso a cinco domicílios, em virtude de tratar-se de uma zona rural da região semi-árida; ausência, em onze domicílios, do familiar que participou do curso de GRH, no momento da visita. Assim, devido às referidas limitações do estudo, na pesquisa entrevistaram-se representantes de 56 famílias.

Realizou-se uma única visita a cada domicílio, sendo a coleta de dados desempenhada por meio de uma entrevista efetuada no domicílio das famílias beneficiadas com as cisternas, que seguiu um formulário estruturado, previamente averiguado por meio de testes-pilotos, aplicados a cinco famílias que também possuíam cisternas, as quais não compuseram a amostra do presente estudo. Além disso, consultou-se o Sistema de Informações de Vigilância Epidemiológica - Doenças Diarréicas Agudas (DDA) de Canindé e o banco de dados do Esplar Centro de Pesquisa e Assessoria, o qual é a Organização NãoGovernamental (ONG) responsável pela implementação do P1MC no referido município.

Os dados foram processados no Statistical Package for Social Science (SPSS), versão 13.0 for Windows e apresentados em tabelas. A análise dos dados ocorreu de maneira descritiva, por meio do cálculo de frequências absolutas e relativas no que diz respeito às variáveis: posição ocupada pelo entrevistado na família, idade, escolaridade, renda familiar, número de moradores por domicílio, fontes de água utilizadas antes da construção das cisternas, formas de tratamento dispensado à água antes e após a construção das cisternas. Além disso, utilizou-se o coeficiente de correlação linear de Pearson entre as variáveis taxa de internamentos por Doenças Diarréicas Agudas (DDA) em menores de cinco anos de idade e número de cisternas construídas, por ano.

$\mathrm{O}$ estudo atendeu às recomendações da Resolução 196/96 do Conselho Nacional de Saúde, que trata sobre pesquisas envolvendo seres humanos. ${ }^{9} \mathrm{O}$ projeto de pesquisa foi submetido à apreciação do Comitê de Ética em Pesquisa da Universidade Federal do Ceará, sendo aprovado, conforme o Protocolo ${ }^{\circ}$ 01/08. Cada sujeito, uma vez esclarecido sobre a finalidade do estudo e os aspectos gerais de sua participação, assinou o Termo de Consentimento Livre e Esclarecido.

\section{RESULTADOS}

A Tabela 1 consolida os dados sociodemográficos dos representantes das famílias beneficiadas pelo P1MC. Dos 56 entrevistados, 43 (76,8\%) ocupavam a posição de mãe na família. A faixa etária predominante foi de adulto-jovem (20 a 39 anos), correspondendo a $23(41,1 \%)$ participantes. Quanto à escolaridade, 30 (53,6\%) tinham o ensino fundamental completo ou incompleto. A renda familiar de até meio salário mínino foi referida por 28 (50\%) famílias entrevistadas. Verificou-se ainda que o número de moradores de 38 (67,8\%) domicílios estudados foi de quatro a nove membros.

Tabela 1 - Distribuição dos participantes da pesquisa segundo características sociodemográficas. Canindé-CE, 2008

\begin{tabular}{lrr}
\hline Variáveis (n=56) & $\mathbf{n}$ & $\mathbf{\%}$ \\
\hline Posição ocupada na família (n=56) & & \\
Mãe & 43 & 76,8 \\
Pai & 5 & 8,9 \\
Filho & 5 & 8,9 \\
Outros & 5,4 \\
Idade (em anos) & 3 & 5,3 \\
18 e 19 & 23 & 41,1 \\
20 a 39 & 19 & 34 \\
40 a 59 & 11 & 19,6 \\
60 ou mais & \\
Escolaridade & 16 & 28,6 \\
Analfabeto & 30 & 53,6 \\
Ensino fundamental (incompleto ou completo & 5 & 8,9 \\
Ensino médio (incompleto ou completo) & 1 & 1,8 \\
Ensino superior (incompleto) & 4 & 7,1 \\
Saber ler e escrever & & \\
Rendimento familiar (em salário mínimo)* & 5 & 8,9 \\
Sem rendimento & 28 & 50 \\
Até 1/2 salário & 21 & 37,5 \\
Mais de 1/2 a 2 & 2 & 3,6 \\
Mais de 2 & & \\
Número de moradores/domicílio & 15 & 26,8 \\
1 a 3 & 38 & 67,8 \\
4 a 9 & 3 & 5,6 \\
10 ou mais & &
\end{tabular}

*salário mínimo vigente $\mathrm{R} \$ 415,00$

A tabela 2 apresenta as principais fontes de água utilizadas pelas famílias estudadas, antes da construção das cisternas, observando-se que 21 (37,5\%) faziam uso da água de cacimbão para o consumo humano, seguido por $17(30,4 \%)$ que utilizavam água de açude. As características da água consumida antes da construção das cisternas foram 
referidas por $35(62,5 \%)$ das famílias entrevistadas como escura/barrenta; por $30(53,6 \%)$, como salobra; e por $15(29,8 \%)$, como contendo pedras; porém $21(37,5 \%)$ famílias a consideraram sem cheiro.

Tabela 2 - Distribuição da fonte de água utilizada pelas famílias estudadas para consumo humano, antes da construção das cisternas. Canindé - CE, 2008

\begin{tabular}{lcc}
\hline Fonte de água $(\mathbf{n = 5 6 )}$ & $\mathbf{n}$ & $\mathbf{\%}$ \\
\hline Cacimbão & 21 & 37,5 \\
Açude & 17 & 30,4 \\
Cacimba & 13 & 23,2 \\
Rio & 9 & 16,0 \\
Carro-pipa & 2 & 3,6 \\
Poço profundo & 1 & 1,8 \\
\hline
\end{tabular}

Além disso, as principais doenças relacionadas às condições da água que acometiam as crianças, antes da construção das cisternas, eram diarréia e verminose, referidas, respectivamente, por $40(71,4 \%)$ e $31(55,4 \%)$ famílias. Contudo, após a construção das cisternas, 47 (83,9\%) entrevistados relataram ter percebido uma redução na ocorrência dessas doenças nas crianças da família.

Conforme a tabela 3 , verifica-se uma correlação linear inversamente proporcional entre a taxa de internações por Doenças Diarréicas Agudas (DDA) e o número de cisternas construídas por ano $(r=-0,943)$, havendo também uma associação estatisticamente significante entre ambas $(p=$ $0,001)$. Dessa maneira, pode-se afirmar que os internamentos por diarréia decresceu ao longo dos últimos oito anos em função do número crescente de cisternas construídas no período estudado.

Tabela 3 - Distribuição da taxa de internações por Doenças Diarréicas Agudas (DDA) em menores de 5 anos de idade e número de cisternas construídas, por ano. Canindé-CE, 2000-2007

\begin{tabular}{lrrrrrrrr}
\hline Ano & $\mathbf{2 0 0 0}$ & $\mathbf{2 0 0 1}$ & $\mathbf{2 0 0 2}$ & $\mathbf{2 0 0 3}$ & $\mathbf{2 0 0 4}$ & $\mathbf{2 0 0 5}$ & $\mathbf{2 0 0 6}$ & $\mathbf{2 0 0 7}$ \\
\hline Número de cisternas construídas & 0 & 0 & 0 & 10 & 71 & 30 & 68 & 102 \\
Taxa de internações por DDA & 43,24 & 38,48 & 42,95 & 37 & 29,66 & 32,6 & 19,8 & 17,37 \\
\hline
\end{tabular}

Fonte: Sistema de Informações de Vigilância Epidemiológica - Doenças Diarréicas Agudas (DDA). Canindé-CE. * $r=-0,930 ; p=0,001$

A tabela 4 apresenta os principais tipos de tratamento realizados com a água destinada ao consumo humano, antes e após a construção das cisternas, sendo a cloração o cuidado mais prevalente nos dois momentos, com $46(82,1 \%)$ e 37 $(66 \%)$, respectivamente. A filtração apresentou-se como a forma de tratamento menos freqüente, sendo realizada por quatro $(7,1 \%)$ famílias antes e por apenas uma $(1,8 \%)$ depois da construção das cisternas. Ressalta-se que das 56 famílias participantes, alguns responsáveis pelos cuidados com a água referiram utilizar mais de uma forma de tratamento da mesma antes do consumo humano. Além disso, antes da construção da cisterna, três $(5,4 \%)$ famílias referiram não realizar nenhum tipo de tratamento na água, enquanto que, após a aquisição do referido reservatório hídrico, este número elevou-se para sete $(12,5 \%)$ famílias.
Tabela 4 - Distribuição do número de representantes das famílias participantes conforme tratamento dispensado pelas famílias à água utilizada para consumo humano, antes e após a construção das cisternas. Canindé - CE, 2008

\begin{tabular}{lrrrr}
\hline \multirow{2}{*}{ Tratamento da água* } & \multicolumn{2}{c}{$\begin{array}{c}\text { Antes da } \\
\text { cisterna }\end{array}$} & \multicolumn{2}{c}{$\begin{array}{c}\text { Depois da } \\
\text { cisterna }\end{array}$} \\
\cline { 2 - 6 } & \multicolumn{1}{c}{$\mathbf{n}$} & \multicolumn{1}{c}{$\%$} & $\mathbf{n}$ & \% \\
\hline Cloração & 46 & 82,1 & 37 & 66,0 \\
Peneiração & 27 & 48,2 & 18 & 32,1 \\
Fervura & 8 & 14,3 & 8 & 14,3 \\
Filtração & 4 & 7,1 & 1 & 1,8 \\
\hline Total & $\mathbf{8 5}$ & $\mathbf{-}$ & $\mathbf{6 4}$ & - \\
\hline${ }^{*}$ =56 & & & &
\end{tabular}




\section{DISCUSSÃO}

A figura da mãe destaca-se no contexto rural devido ao fato de ela permanecer mais tempo em casa do que os demais membros da família, cuidando dos filhos e realizando tarefas domésticas. Além disso, famílias chefiadas por mulheres são priorizadas pelo P1MC para serem beneficiadas com as cisternas. ${ }^{8}$

A agricultura ainda é a profissão/ocupação predominante em comunidades rurais ${ }^{10}$. Contudo, as secas representam obstáculos para o crescimento e para a melhoria do bem-estar das populações do semi-árido, provocam desequilíbrios econômicos, sociais e ambientais, afetando a pequena agricultura de sequeiro (milho, feijão e mandioca), predominantemente de subsistência e fortemente associada à situação de extrema pobreza, pelo que a falta dessa reserva de alimentos tem acarretado fome crônica e subnutrição. ${ }^{11}$

Ressalta-se que, no presente estudo, 28 (50\%) participantes possuíam renda familiar de até $1 / 2$ salário mínimo, ou seja, menos de $R$ \$225,50, para sustentar famílias compostas inclusive por onze pessoas. Além disso, cinco famílias não possuíam renda, vivendo da agricultura de subsistência ou do auxílio de moradores da comunidade. A pesquisa identificou que crianças residentes em domicílios caracterizados por condições sanitárias insatisfatórias, com famílias numerosas e com baixo poder aquisitivo, em um mês, possuíram prevalência de diarréia de $55,7 \%{ }^{12}$

No presente estudo verificou-se que as principais fontes de água utilizadas pelas famílias participantes, antes da construção das cisternas, foram o cacimbão e o açude. O primeiro trata-se de uma cacimba grande ou poço no qual se acumula água proveniente do subsolo, enquanto que os açudes são construções destinadas a represar águas de rio, a fim de servirem, por exemplo, para rega, sendo construídos para compensar a escassez de água de superfície e suportar os longos períodos de estiagem. Os açudes permitem a realização de práticas agrícolas e de pecuária, e quando as outras fontes de água vão se esvaindo, estes se tornam prioridade para suprir as necessidades hídricas da população. ${ }^{13}$

Entretanto, a água dos rios, represada em açudes, é vítima do mau uso por parte das pessoas, sendo a disseminação de agrotóxicos um dos principais responsáveis por sua contaminação. ${ }^{14}$ Estudo realizado em Minas Gerais, com relação aos rios, verificou que: o gado e outros animais pisam, urinam e defecam em suas águas; criações morrem perto dos mesmos; em suas proximidades localizam-se chiqueiros e currais, condições que contribuem para a má qualidade de suas águas; pessoas tomam banho e lavam roupas. Mas, mesmo assim, na escassez, acabam por consumir água dessas fontes. ${ }^{15}$

Em relação às características da água destinada ao consumo humano foi verificado que na sub-bacia de Santa Cruz-MG, em $60 \%$ das propriedades, a água para os animais provinha da mesma fonte que a água para o consumo doméstico. Além disso, nas análises de água realizadas na pesquisa, 93\% das amostras da fonte apresentavam número de coliformes fecais acima do padrão de potabilidade padronizado pela Portaria 36/GM de 1990. Em relação às propriedades da sub-bacia Água Limpa-MG, 15\% dos entrevistados citaram que a água consumida apresentava alguma cor, $4 \%$ citaram que havia odor, e $78 \%$ que percebem sujeira na água. Porém, a ocorrência de doenças veiculadas pela água aos seres humanos foi citada em apenas $11 \%$ das propriedades. ${ }^{10}$

Estudo realizado em 30 propriedades leiteiras situadas no Estado de São Paulo objetivou saber a opinião dos moradores sobre a qualidade da água por eles consumida, tendo sido observado que $100 \%$ das pessoas entrevistadas consideraram a água das propriedades de boa qualidade, talvez devido a isso observou-se a ausência de qualquer tratamento da água consumida e o pequeno número de residências que utilizavam filtros. Apesar disso, 90\% das amostras de água das fontes, 90\% dos reservatórios e $96,7 \%$ de água de consumo humano, colhidas no período de chuvas, e $83,3 \%$, $96,7 \%$ e $90 \%$, daquelas colhidas respectivamente nos mesmos locais, durante a estiagem, estavam fora dos padrões microbiológicos de potabilidade para água de consumo humano. ${ }^{16}$

O consumo de água das fontes por longos períodos sem a ocorrência de problemas de saúde evidentes, somando-se a uma sensação de pureza que o bom aspecto da água proporciona aos consumidores, contribuem para a não adesão aos tratamentos à água destinada ao consumo humano.

As crianças, em decorrência de comportamentos de risco associados a fatores fisiológicos, como a imaturidade do sistema imunológico, são vulneráveis à aquisição de inúmeras doenças, como doenças diarréicas e enteroparasitoses, apesar de serem consideradas enfermidades de caráter evitável. Torna-se ainda relevante salientar que a saúde de crianças na faixa etária de zero a cinco anos reflete a contaminação do meio em que elas vivem. ${ }^{17}$ 
Diarréia, a doença que mais acometia as crianças antes da construção das cisternas, segundo as famílias participantes do presente estudo, constitui-se no aumento da freqüência dos movimentos intestinais (mais de três por dia), aumento da quantidade de fezes (mais de 200g/ dia) e consistência alterada das fezes, geralmente associada à vontade rápida, desconforto perianal, incontinência ou com uma combinação desses fatores. A diarréia aguda é autolimitante, estando, muitas vezes, associada a distúrbios virais ou bacterianos. ${ }^{18}$

A prevalência da diarréia em menores de dois anos, em áreas que possuem Programa de Agentes Comunitários de Saúde (PACS) e Programa Saúde da Família (PSF) são maiores na região Norte do Brasil, com 9,8\% e 8,8\% de incidência, respectivamente. No Nordeste, a segunda região brasileira com maior número de casos de diarréia detectados, em 2002, apresentou incidência de $6,9 \%$ e 7,9\% nas áreas que possuem PACS e PSF, respectivamente; tendo o Ceará se deparado com estatística superior, 9,2\% de casos. ${ }^{19}$

Em relação ao $\mathrm{P} 1 \mathrm{MC}$, de acordo com dados obtidos no Esplar, o início da construção de cisternas, em Canindé-CE, ocorreu no mês de novembro de 2003, com a implantação de dez cisternas. De 2003 para 2004, houve um incremento na construção das mesmas, período em que as taxas de internações por DDA em menores de cinco anos reduziram. Em 2005 foram construídas menos cisternas, apenas 30 , e, neste ano, comparativamente ao anterior, houve uma elevação nas taxas de internação por diarréias no município. O crescente número de cisternas construídas nos anos de 2005, 2006 e 2007; 30, 68 e 102 cisternas, respectivamente, pode ter influenciado na redução na taxa de internação por DDA $(r=-0,943 ; p=0,001)$.

Comparando-se a ocorrência de internações por diarréia em crianças entre os anos de 2000 a 2007 e a construção de cisternas no município no mesmo período, a taxa de DDA passou de 43,3 para 17,37 e o número de cisternas passou de zero, em 2000, para 102, no ano de 2007, configurando, portanto, uma correlação linear inversamente proporcional, entre a taxa de internamentos por DDA e o ano ( $r=-0,930 ; \mathrm{p}=0,001)$.

Estudo que analisou a morbidade por diarréia em 650 crianças, com idade entre um ano completo e cinco anos incompletos, residentes em áreas de assentamento subnormal em Juiz de Fora-MG, observou que a prevalência da diarréia foi $17,5 \%$, sendo o consumo de água de origem duvidosa citado como um fator de risco coletivo para a sua ocorrência. ${ }^{20}$

Além da diarréia, as enteroparasitoses constituem-se uns dos principais problemas existentes na saúde pública, especialmente nos países em desenvolvimento. ${ }^{21}$ Os índices de enteroparasitoses em humanos são consideravelmente elevados. Em 2001, de cada 100.000 habitantes do país, 25,58 foram a óbito por doenças infecciosas ou parasitárias de acordo com a classificação da décima revisão da Classificação Internacional de Doenças e de Problemas Relacionados à Saúde (CID 10), tendo o Nordeste alcançado o segundo menor índice entre as regiões brasileiras, com 23,57 óbitos por 100.000 habitantes. ${ }^{22}$

A água pluvial é naturalmente destilada e apropriada para o consumo humano, entretanto a qualidade da água da chuva coletada depende do armazenamento e do manejo das formas de tratamento empregadas antes do consumo. Em períodos de baixo índice pluviométrico, uma das primeiras conseqüências é a queda da qualidade da água, fato que acarreta doenças que atingem a população em geral, mas principalmente as crianças. ${ }^{23}$

O melhor método de assegurar água adequada para o consumo consiste em formas de proteção, evitando-se contaminação por dejetos animais e humanos, os quais podem conter grande variedade de bactérias, vírus, protozoários e helmintos. Falhas na proteção e no tratamento efetivo contra essas impurezas expõem a comunidade a riscos de contaminação por doenças intestinais infecciosas. ${ }^{24}$

O Ministério da Saúde (MS) e secretarias estaduais e municipais de saúde recomendam, pela simplicidade, baixo custo e eficácia, a utilização de soluções de hipoclorito para a desinfecção de água em regiões onde não existe saneamento básico, como medida preventiva no combate às doenças de veiculação hídrica. O cloro tem amplo uso como desinfetante químico para água de abastecimento público, seu uso contínuo e com diluição correta assegura a eliminação de patógenos causadores de toxinfecções, tais como os responsáveis pela cólera, desinteria, febre tifóide, hepatite e outras..$^{25}$

A quantidade de hipoclorito de sódio a 2,5\% recomendada pela Secretaria de Vigilância em Saúde do MS, para o tratamento da água antes do consumo humano, é de duas gotas por litro, deixando a solução repousar por 30 minutos antes do uso. ${ }^{26}$

Analisando-se a diluição referida pelas 46 $(82,1 \%)$ famílias que utilizavam o hipoclorito de 
sódio no tratamento da água antes das cisternas, apenas $5(10,8 \%)$ realizavam a diluição correta. As diluições de hipoclorito mais praticadas pelos participantes do estudo foram de uma gota para cada litro de água, referida por 10 (21,7\%) famílias, e uma gota para cada dois litros, realizada em 9 (19,6\%) famílias, havendo, ainda, alguns que referiram diluir uma gota para cada trinta litros. Além disso, um dos entrevistados referiu diluir cinco gotas em um litro e meio, outros sete colocavam o cloro sem medida ou não sabiam informar.

A peneiração apareceu como segundo método de tratamento escolhido pelas famílias, tanto antes, praticada por $27(48,2 \%)$, quanto depois da construção das cisternas, realizada por 18 (32,1\%). As famílias da zona rural do Ceará costumam armazenar água para a ingesta humana em potes de barro, mas antes "coam" a água com pano próprio para esse fim. Entretanto, esse cuidado apenas retira parte das impurezas macroscópicas, sendo necessário um segundo método que realmente trate a água tornando-a adequada ao consumo humano.

Estudo realizado em Lavras-MG, na subbacia Água Limpa, verificou que 30 (56\%) entrevistados da localidade não tratavam a água antes do consumo e, apenas, $7 \%$ utilizavam a filtração. Em relação à sub-bacia Santa Cruz-MG, poucos entrevistados faziam algum tratamento que visasse eliminar microrganismos da água, e desses, um (7\%) informou ferver, e $3(20 \%)$ utilizavam cloro. ${ }^{10}$

De acordo com pesquisa realizada no Distrito de São João dos Queiroz-CE, 46 (25,8\%) dos 179 entrevistados responderam que cloravam água, enquanto $70(39,3 \%)$ não utilizavam qualquer tratamento. Além disso, os participantes do referido estudo relataram utilizar filtros, coagem em pano e fervura, sendo identificada resistência da população para fazer uso do hipoclorito para o tratamento da água. ${ }^{27}$

No presente estudo as formas de tratamento da água foram citadas 85 vezes, antes da obtenção das cisternas, ao passo que, após sua construção, esse número reduziu para 64. A quantidade de famílias que utilizavam a fervura como forma de tratamento manteve-se constante tanto na presença quanto na ausência das cisternas. Em relação à filtração, três das quatro famílias que utilizavam esse método deixaram de fazê-lo após a aquisição das cisternas. Esse comportamento pode dever-se ao fato de as famílias acreditarem que a água da chuva é potável e livre de impurezas, apesar de que a água da cisterna como de qualquer outro reservatório pode apresentar-se contaminada devido a inúmeros fatores relacionados ao manejo inadequado da mesma.

Ressalta-se a importância de esclarecer às famílias quanto ao correto tratamento da água, o adequado manejo e cuidado com as cisternas, tais como: calçada ao redor da fonte; tampa; parede externa acima do solo; revestimento interno; localização no ponto mais alto do terreno; e fossa com distância maior que trinta metros. Pesquisa realizada no Estado de São Paulo, com o objetivo de verificar o papel da água como fator de risco para a saúde dos consumidores, demonstrou que nenhuma fonte apresentou $100 \%$ dos fatores indicados para sua proteção. ${ }^{28}$

Ressalta-se que para que uma intervenção venha a ser eficaz, torna-se essencial que tome como objeto os problemas de saúde da comunidade e seus determinantes, organizando a atenção de forma a incluir não apenas as doenças e suas complicações, mas também as ações que incidam sobre as causas, como condições de vida, alimentação, moradia, trabalho e lazer. ${ }^{29}$

Assim, o enfermeiro, diante do impacto positivo do uso de cisternas que captam água pluvial para o consumo humano, deve ampliar o seu cuidado, inserindo em suas atividades de educação em saúde a problemática ambiental, ${ }^{30}$ visto que está intrinsecamente relacionada à saúde da população. Além disso, o mesmo pode valer-se de visitas domiciliárias para averiguar o cotidiano dessas famílias, orientando seus hábitos diários, favorecendo ainda o acesso aos serviços, a construção de novas relações e maior vínculo entre a população e os profissionais.

Dessa maneira, acredita-se que as intervenções respondam de forma mais abrangente às necessidades vividas, ${ }^{31}$ seja em relação aos cuidados com a captação, armazenamento e manejo adequado da água das cisternas, seja quanto ao seu correto tratamento antes de ser utilizada para o consumo humano.

Diante das informações obtidas por meio do presente estudo, aconselha-se que os enfermeiros devam, inicialmente, conhecer o P1MC, para que possam reforçar as informações fornecidas pelo programa, bem como complementá-las, com o intuito de tornar possível a garantia de continuidade do acompanhamento das famílias beneficiadas com as cisternas no sentido de orientá-las quanto aos principais cuidados que devem ser realizados com a água destinada ao consumo humano. 


\section{CONCLUSÕES}

Apesar de ter-se observado uma associação inversamente proporcional entre a construção das cisternas do P1MC e o comportamento das diarréias em crianças menores de cinco anos no município de Canindé-CE, não se pode afirmar que essa é a única causa da redução das taxas de internamento por DDA, nessa faixa etária. Podese inferir que realmente houve uma melhoria na qualidade da água consumida pelas famílias, visto que, antes da construção das cisternas, ingeriam água proveniente, em sua maioria, de cacimbões e de açudes, a qual era escura/barrenta, salobra e com pedras, porém sem cheiro.

Verificou-se a necessidade de maiores esclarecimentos e adesão da população a medidas de tratamento da água, tendo em vista a redução da realização de tratamento adequado após a construção das cisternas, ou seja, mesmo tendo participado do curso de Gestão de Recursos Hídricos, essas famílias podem estar entendendo que a água da cisterna, por ser proveniente da chuva, já está apta ao consumo humano. Contudo, sabe-se que as impurezas presentes no telhado da casa, e na própria cisterna, por exemplo, podem comprometer a potabilidade dessa água.

Assim, torna-se necessário o desenvolvimento de um trabalho de educação em saúde e um maior acompanhamento por parte de enfermeiros no que concerne à escassez de recursos hídricos por conta de fatores ambientais, bem como adoção de medidas de prevenção de doenças veiculadas pela água e intervenções que busquem promover a saúde desta população, sobretudo das crianças.

\section{REFERÊNCIAS}

1. Freitas CM, Porto MF. Saúde, ambiente e sustentabilidade. Rio de Janeiro (RJ): Editora Fiocruz, 2006.

2. Matos MIS. Água: o desafio da saúde no século XXI. Pastoral das comunicações- Boletim Diocesano [online]. 2006 [acesso 2008 Ago 31]; 9(131). Disponível em: http://www.diocesefranca.org.br/boletim/ out2006/bd-notpsaude.html

3. Tucci CEM, Hespanhol I, Cordeiro Netto OM. A gestão da água no Brasil: uma primeira avaliação da situação atual e das perspectivas para 2025 [página da internet]. Brasília (DF): UnB; 2010 [acesso 2008 Ago 25]. Disponível em: http://www.unb.br/ft/ enc/recursoshidricos/relatorio.pdf

4. Bloch D. Água: direito à vida. Recife (CE): Cáritas Brasileira, IRPAA, UNICEF; 2001.
5. Ministério da Saúde (BR). Sistema de Informações de Mortalidade C.6 Mortalidade proporcional por doença diarreica aguda em menores de 5 anos de idade [página da internet]. Ministério da Sáude, 2006 [acesso 2008 Ago 31]. Disponível em: http:/ / tabnet. datasus.gov.br/cgi/tabcgi.exe?idb2006/c06.def

6. BittencourtSA, Leal MC, Santos MO. Hospitalization due of infectious diarrhea in Rio de Janeiro State. Cad Saúde Pública. 2002 Mai-Jun; 18(3):747-54.

7. Cezar-Vaz MR, Weis AH, Costa VZ, Soares JFS, Bonow CA, Cardoso LS, et al. Estudo com enfermeiros e médicos da atenção básica à saúde: uma abordagem socioambiental. Texto Contexto Enferm. 2007 Out-Dez; 16(4):645-53.

8. Articulação no Semi-árido (ASA). Programa de formação e mobilização social para a convivência com o Semi-Árido: um milhão de cisternas rurais (P1MC). Recife (CE): ASA; 2002.

9. Ministério da Saúde (BR), Conselho Nacional de Saúde, Comissão Nacional de Ética em Pesquisa. Resolução no 196 de 10 de outubro de 1996: diretrizes e normas regulamentadoras de pesquisa envolvendo seres humanos. $2^{\mathrm{a}}$ ed. Brasília (DF): MS; 2003.

10. Rocha CMBM, Rodrigues LS, Costa CC, Oliveira PR, Silva IJ, Jesus EFM, et al. Avaliação da qualidade da água e percepção higiênico-sanitária na área rural de Lavras, Minas Gerais, Brasil, 1999-2000. Cad Saúde Pública. 2006 Set; 22(9):1967-78.

11. Fernandes FBP. Gestão de recursos hídricos nas regiões áridas e semi-áridos como um processo de redução das desigualdades sociais. In: Hermanns $\mathrm{K}$, editor. Água e desenvolvimento sustentável no Semi-Árido. Fortaleza (CE): Fundação Konrad Adenauer; 2002. p. 69-86.

12. Borges CVD, Veiga APB, Barroso GS, Jesus EFO, Serpa RFB, Moreira S, Salles-Costa R. Associação entre concentrações séricas de minerais, índices antropométricos e ocorrência de diarréia entre crianças de baixa renda da região metropolitana do Rio de Janeiro. Rev Nutr. 2007 Mar-Abr; 20(2):159-69.

13. Gazin P, Barbosa CS, Bouvy M, Audry P. Registro de ocorrência de vetores da esquistossomose mansônica em açude do Sertão de Pernambuco. Rev Soc Bras Med Trop. 2000 Jul-Ago; 33(4):407-8.

14. Moreira JC, Jacob SC, Peres F, Lima JS, Meyer A, Oliveira-Silva JJ, et al. Avaliação integrada do impacto do uso de agrotóxicos sobre a saúde humana em uma comunidade agrícola de Nova Friburgo, RJ. Ciênc Saúde Coletiva. 2002; 7(2):299-311.

15. Ribeiro EM, Galizoni FM. Água, população rural e políticas de gestão: o caso do vale do Jequitinhonha, Minas Gerais. Ambient Soc. 2003 Jan-Jul; 6(1):129-46.

16. Amaral LA, Nader Filho A, Rossi Junior OD, Ferreira FLA, Barros LSS. Água de consumo humano com fator de risco à saúde em propriedades rurais. Rev Saúde Pública. 2003 Ago; 37(4):510-4. 
17. Garcia JGD. Comparação de quatro métodos laboratoriais para o diagnóstico da Giardia lamblia em fezes de crianças da região de Araraquara SP [dissertação]. Araraquara (SP): Universidade Estadual Paulista, Faculdade de Ciências Farmacêuticas; 2005.

18. Smeltzer SC, Bare BG. Tratado de enfermagem médico-cirúrgica. $10^{\mathrm{a}} \mathrm{ed}$. Rio de Janeiro: Guanabara Koogan; 2005.

19. Ministério da Saúde (BR). Sistema de Informação da Atenção Básica (SIAB). Situação de saúde da população coberta pelo PACS/PSF [página da internet]; 2002 [acesso 2008 Jun 7]. Disponível em: http://dtr2002.saude.gov.br/caadab/1999/ Grafico \% 20-\%20PACS\%20\&\%20PSF \% 2099 Diarr\%E9ia\%20e\%20IRA.pdf.

20. Teixeira JC, Heller L. Fatores ambientais associados à diarréia infantil em áreas de assentamento subnormal em Juiz de Fora, Minas Gerais. Rev Bras Saude Mater Infant. 2005 Out-Dez; 5(4):449-55.

21. Hurtado-Guerrero AF, Alencar FH, HurtadoGuerrero JC. Ocorrência de enteroparasitas na população geronte de Nova Olinda do Norte Amazonas, Brasil. Acta Amaz. 2005 Out-Dez; 35(4):487-90.

22. Ministério da Saúde (BR). Coordenação Geral de Informações e Análise Epidemiológica. Análise dos Dados de Mortalidade de 2001[página da internet]. Brasília (DF): MS; 2004 [acesso 2008 Jun 7]. Disponível em: http:/ / portal.saude.gov.br/portal/ arquivos/pdf/mortalidade\%202001.pdf.

23. Benyus JM. Biomimicry: Innovations inspired by Nature. Nova York (US): William Morrow, 2000.

24. Heller L. Relação entre saúde e saneamento na perspectiva do desenvolvimento. Ciênc Saúde Coletiva. 1998 Jan-Jun; 3(2):73-84.
25. Ministério da Saúde (BR). Indicadores de morbidade e fatores de risco. Brasília (DF): Ministério da Saúde; 2006.

26. Ministério da Saúde (BR). Saúde reforça apoio ao controle de doenças diarréicas no Acre. Portal da Saúde [página da internet], 03 Out 2005 [acesso 2008 Jun 08]. Disponível em: http://portal.saude.gov. $\mathrm{br} /$ portal/aplicacoes/noticias/noticias_detalhe. cfm?co_seq_noticia $=20909$

27. Mello DA, Rouquayrol MZ, Araújo D, Amadei $\mathrm{M}$, Souza J, Bento LF, et al. Promoção à saúde e educação: diagnóstico de saneamento através da pesquisa participante articulada à educação popular (Distrito São João dos Queiroz, Quixadá, Ceará, Brasil). Cad Saúde Pública. 1998 Jul-Set; 14(3):583-95.

28. Blackburn DM, Bustamante Y, Jalfim F, Viana AA, Farias Júnior M, Lima M. Avaliação de potabilidade da água na região de atuação da Diaconia no semiárido nordestino. Recife (CE): Diaconia; 2005.

29. Shimizu Helena Eri, Rosales Carlos. As práticas desenvolvidas no Programa Saúde da Família contribuem para transformar o modelo de atenção à saúde? Rev Bras Enferm [periódico na Internet]. 2009 Jun [acesso 2009 Ago 20]; 62(3):424-9. Disponível em: http://www.scielo.br/pdf/reben/ v62n3/14.pdf

30. Ministério da Saúde (BR). Departamento de Atenção Básica. Guia Prático do Programa de Saúde da Família. Brasília (DF): Ministério da Saúde; 2004.

31. Mandú ENT, Gaíva MAM, Silva MA, Silva AMN. Visita domiciliária sob o olhar de usuários do programa saúde da família. Texto Contexto Enferm. 2008 Jan-Mar; 17(1):131-40. 